\title{
Manual Versus Target-Controlled Infusion Remifentanil Administration in Spontaneously Breathing Patients
}

Annelies T. Moerman, MD*

Luc L. Herregods, MD, PhD*

Martine M. De Vos, MD, PhD十

Eric P. Mortier, MD, Dsc ${ }^{*} \ddagger$

Michel M. R. F. Struys, MD, PhD $\ddagger \S$
BACKGROUND: The combination of propofol-remifentanil for procedural deep sedation in spontaneously breathing patients is characterized by the frequent incidence of side effects, especially respiratory depression. These side effects may be due to either the drug combination or the drug delivery technique. Target-controlled infusion (TCI) might optimize drug delivery. In this prospective, randomized, double-blind study in patients undergoing elective colonoscopy, we thus tried to answer two questions: first, if adding remifentanil to propofol surpasses the disadvantages of the combination of these two products, and second, if administration of remifentanil via TCI decreases the incidence of side effects, compared to manually controlled administration.

METHODS: Patients undergoing elective colonoscopy were randomly assigned to receive remifentanil via manually controlled continuous infusion (MCI) $(0.125$ $\mu \mathrm{g} \cdot \mathrm{kg}^{-1} \cdot \mathrm{min}^{-1}$ for $2 \mathrm{~min}$ followed by a continuous infusion of 0.05 $\left.\mu \mathrm{g} \cdot \mathrm{kg}^{-1} \cdot \mathrm{min}^{-1}\right)$, TCI remifentanil $(1 \mathrm{ng} / \mathrm{mL}$ ), or placebo (normal saline either as TCI or manual infusion of equivalent rate). All patients received TCI propofol, adjusted to a target concentration level that provided deep sedation in which patients were not responsive to verbal commands, but maintained spontaneous ventilation without assistance.

RESULTS: Significantly more patients in the placebo group showed movement, cough and hiccup, which transiently interfered with the examination. There were no clinically significant differences in hemodynamic or recovery variables among all groups. Remifentanil administered via TCI resulted in a decrease in propofol requirements. The incidence of hypopnea and apnea was less frequent when remifentanil was administered via TCI compared to MCI (TCI $n=7, \operatorname{MCI} n=16$, $P<0.05)$.

CONCLUSION: The combination of remifentanil and propofol for deep sedation in spontaneously breathing patients, offered better conditions for colonoscopy than propofol used as a single drug. Remifentanil administered via TCI resulted in a decrease in propofol dosing and in a lower incidence in apnea and respiratory depression (TCI $n=7$, MCI $n=16, P<0.05$ ), compared to manually controlled administration of remifentanil.

(Anesth Analg 2009;108:828-34) or deep sedation in spontaneously breathing patients, the combination of propofol and remifentanil is increasing in popularity. However, the ability to provide adequate amnesia, immobility and analgesia is limited by the ventilatory depression associated with both propofol and remifentanil. ${ }^{1-4}$ The combination of

From the Departments of *Anesthesiology and +GastroEnterology, Ghent University Hospital; †Department of Anesthesiology, Ghent University, Gent, Belgium; and §Department of Anesthesiology, University Medical Center Groningen, University of Groningen, Groningen, The Netherlands.

Accepted for publication December 4, 2008.

No financial support from foundations, institutions, pharmaceutical, or other private companies was involved in this work.

Address correspondence and reprint requests to Annelies Moerman, MD, Department of Anesthesiology, Ghent University Hospital, De Pintelaan 185, 9000 Gent, Belgium. Address e-mail to annelies.moerman@ugent.be.

Copyright (C) 2009 International Anesthesia Research Society DOl: 10.1213/ane.0b013e318198f6dc both products, even in low doses, results in a strikingly synergistic respiratory depression. ${ }^{5}$ In previous work, we compared manually controlled infusion (MCI) of remifentanil versus placebo to supplement MCI propofol during spontaneous respiration. ${ }^{1} \mathrm{We}$ concluded that, due to the enormous interindividual variability in calculated effect-site concentrations, MCI remifentanil in combination with MCI propofol is not a reliable technique during spontaneous respiration.

The administration of drugs via target-controlled infusion (TCI) allows achievement of a defined target concentration without overshoot and overdosing, ${ }^{6}$ which is common when using manual infusions ${ }^{1}$ and which is responsible for the respiratory side effects. ${ }^{7}$ TCI versus MCI of remifentanil used to supplement propofol during spontaneous respiration has not been compared. The aim of this study was twofold. First, to examine if the addition of remifentanil to propofol TCI would result in more beneficial conditions during procedural deep sedation, and second, if there was a 
further benefit if remifentanil was administered via TCI compared to manual administration. Therefore, we evaluated the effect of these regimens with regards to (a) calculated propofol and remifentanil plasma and effect-site concentrations, (b) hemodynamic and recovery variables, and (c) adverse events, with a special focus on respiratory side effects. We hypothesized that remifentanil administration via TCI would exhibit fewer respiratory effects, and thus contribute to a safer and more reliable technique for coadministration of propofol and remifentanil in spontaneously breathing patients.

We want to emphasize that patients undergoing colonoscopy were only chosen as a study population. The reader must be cautioned that this article is not at all meant to make any clinical recommendations concerning deep sedation for colonoscopy.

\section{METHODS}

After local Ethics' Committee (Ethics' Committee, Ghent University Hospital, Gent, Belgium) approval, written informed consent was obtained from all patients. Sixty nonpremedicated outpatients, ASA physical status I or II, ages $18-65 \mathrm{yr}$, scheduled for a complete colonoscopy were randomly included in the study. Patients with a history of allergic reactions to any of the study drugs or chronically receiving opioid analgesics or sedative medication were excluded. All patients received $45 \mathrm{~mL}$ Fleet phospho soda for bowel preparation.

Patients received no preanesthetic medication. After consent had been obtained, but before any anesthetic or surgical interventions, successive envelopes containing allocation to one of the three treatment groups were opened by the deep sedation nurse when patients were in the preoperative holding area. Two groups received remifentanil, one group with MCI (MCI R group, $n=$ $19)$, the other group with TCI (TCI R group, $n=20$ ). The third group received placebo (normal saline, $n=21$ ). To exclude bias and maintain blinding, patients received normal saline either via MCI $(n=11)$ or TCI $(n=10)$. Except for the nurse opening the envelope and preparing the syringes, everyone was blinded. This nurse did not take part further in the study. Blinding was guaranteed by providing the remifentanil or normal saline in coded syringes identified only with the treatment number and patient's initials. Peripheral IV access was established at the opposite arm of the noninvasive blood pressure cuff and a $500 \mathrm{~mL}$ crystalloid infusion was commenced. The solution of remifentanil $(20 \mu \mathrm{g} / \mathrm{mL})$ or placebo and propofol were connected directly to the IV cannula using a three-way tap. In the groups receiving TCI, the target plasma concentration of the study drug (remifentanil or normal saline) was set at $1 \mathrm{ng} / \mathrm{mL}$. In the $\mathrm{MCI}$ group, the study drug infusion was started at a rate of $0.125 \mu \mathrm{g} \cdot \mathrm{kg}^{-1} \cdot \mathrm{min}^{-1}$ for $2 \mathrm{~min}$ (i.e., a bolus dose of $0.25 \mu \mathrm{g} / \mathrm{kg}$ given over $2 \mathrm{~min}$ ), followed by a continuous infusion of $0.05 \mu \mathrm{g} \cdot \mathrm{kg}^{-1} \cdot \mathrm{min}^{-1}$. For calculation of the infusion rate, total body weight was used. The remifentanil infusions (in the MCI group) or the target plasma concentrations (in the TCI group) were kept at the same rate/concentration throughout the procedure. Two minutes after the start of remifentanil/placebo, propofol administration was started using plasmacontrolled TCI, at an initial target concentration of 4 $\mu \mathrm{g} / \mathrm{mL}$ in all 3 groups. When loss of consciousness (LOC) was achieved, which was defined as unresponsiveness to both verbal and tactile stimuli, the target plasma concentration of propofol ( $\left.\mathrm{C}_{\mathrm{p}} \mathrm{prop}\right)$ was set at the same concentration as the calculated effect-site concentration of propofol ( $\mathrm{C}_{\mathrm{e}}$ prop) at which LOC occurred. When LOC was not achieved at $\mathrm{C}_{\mathrm{e}}$ prop 4 $\mu \mathrm{g} / \mathrm{mL}, \mathrm{C}_{\mathrm{p}}$ prop was increased stepwise by $1 \mu \mathrm{g} / \mathrm{mL}$ until LOC, allowing plasma effect-site equilibration between every step, which could be read out in RUGLOOP II ${ }^{\circledR}$ (Demed, Temse, Belgium). Colonoscopy was then started. Propofol administration was adjusted to a level of deep sedation in which patients were no longer responsive to verbal commands and had no purposeful movements or verbal expressions of discomfort, while maintaining spontaneous ventilation without assistance. The target $C_{p}$ prop was increased by $0.5 \mu \mathrm{g} / \mathrm{mL}$ every minute, if necessary, to meet this goal. If the patient was unresponsive for 3 min, the target $C_{p}$ prop was decreased by $0.5 \mu \mathrm{g} / \mathrm{mL}$.

Propofol and remifentanil were administered via a computer-assisted continuous infusion device (RUGLOOP II) to a target plasma concentration using a threecompartment model enlarged with an effect-site compartment. For propofol and remifentanil, the pharmacokinetic-dynamic model previously published by Schnider et al. ${ }^{8,9}$ and Minto et al. ${ }^{10,11}$ were used, respectively. Calculated $\mathrm{C}_{\mathrm{e}}$ prop was computed to yield a time-to-peak effect ${ }^{12}$ of $1.6 \mathrm{~min}$ after bolus injection, as also published by Schnider et al. ${ }^{8,9}$ and used clinically by Struys et al. ${ }^{13}$ For remifentanil, an equilibration time constant (ke0) of 0.595-0.007 (age 40) was applied as published by Minto et al. ${ }^{10,11}$ Propofol and remifentanil infusion were administered using a Fresenius Modular DPS Infusion Pump connected to a Fresenius Base A (Fresenius Vial Infusion Systems, Brézins, France). RUGLOOP II steers the pump at infusion rates between 0 and $1200 \mathrm{~mL} / \mathrm{h}$ via an RS-232 interface. RUGLOOP II was also used to record the Bispectral Index (BIS) signal (BIS XP Monitor A 2000, Aspect Medical Systems, Newton, MA) and noninvasive arterial blood pressure, heart rate $(\mathrm{HR})$, end tidal carbon dioxide $\left(\mathrm{EtCO}_{2}\right)$, respiratory rate (RR), and oxygen saturation $\left(\mathrm{SaO}_{2}\right)(\mathrm{AS} 3$ monitor, Datex, Helsinki, Finland). HR, $\mathrm{EtCO}_{2}, \mathrm{RR}, \mathrm{SaO}_{2}$, and BIS were acquired every $10 \mathrm{~s}$. BIS (version 4.0) was derived from the frontal electroencephalogram (AtFpzt) using a BIS XP-Sensor ${ }^{\circledR}$ (Aspect Medical Systems, Newton, MA). Artifacts in the BIS caused by poor signal quality were automatically detected and excluded from further analysis. Arterial blood pressure was acquired every $3 \mathrm{~min}$. All data were stored 
on hard disk. Supplemental oxygen $(5 \mathrm{~L} / \mathrm{min})$ was supplied by facemask, modified to permit monitoring of $\mathrm{EtCO}_{2}$, RR, and respiratory pattern.

If no polyps were noticed on insertion of the scope, administration of both propofol and study drug were discontinued after the cecum was reached. If polyps were noted, propofol and study drug were discontinued after polypectomy. Duration of deep sedation was calculated as the time from the start of the study product administration to discontinuation of administration. Duration of colonoscopy was calculated from scope in to scope out.

The occurrences of any unwanted effects, such as movement, inadequate respiration, cardiovascular side effects and any adverse events or experiences, were noted. Any intervention to restore normal physiology or respiration was noted.

Immediate recovery was assessed using the Steward Post Recovery Score (SPRS). ${ }^{14}$ The times at which the patients spontaneously opened their eyes, were able to follow the command to squeeze the investigator's hand and were able to state their date of birth were recorded.

Post hoc all respiratory data were visually inspected. Artifacts in $\mathrm{EtCO}_{2}$ monitoring and RR caused by poor signal quality were excluded from further analysis.

\section{Statistical Analysis and Data Presentation}

Statistical power was estimated using a blinded intermittent analysis based on groups of 20 patients with apnea as the primary end-point. The applied test

Table 1. Demographic Data

\begin{tabular}{lccc}
\hline & $\begin{array}{c}\text { MCI R } \\
\text { group }\end{array}$ & $\begin{array}{c}\text { TCI R } \\
\text { group }\end{array}$ & $\begin{array}{c}\text { Placebo } \\
\text { group }\end{array}$ \\
\hline Number $(n)$ & 18 & 18 & 21 \\
Sex $(\mathrm{male} /$ female) & $8 / 10$ & $6 / 12$ & $5 / 16$ \\
Age $(\mathrm{yr})^{a}$ & $39.4 \pm 12.5$ & $41.0 \pm 13.6$ & $39.9 \pm 10.7$ \\
${\text { Height }(\mathrm{cm})^{a}}^{\text {Weight }(\mathrm{kg})^{a}}$ & $169.8 \pm 9.1$ & $169.1 \pm 11.2$ & $167.4 \pm 7.1$ \\
$\begin{array}{c}\text { ASA physical } \\
\quad \text { status (I/II) }\end{array}$ & $158.7 \pm 12.1$ & $66.4 \pm 14.5$ & $73.7 \pm 14.5$ \\
$\begin{array}{c}\text { Indication (D/C/ } \\
\quad \text { P/UC) }\end{array}$ & $13 / 2 / 3 / 0$ & $17 / 1$ & $15 / 6$ \\
\hline
\end{tabular}

$\mathrm{MCl}=$ manually controlled infusion; $\mathrm{TCl}=$ target-controlled infusion; $\mathrm{D}=$ diagnostic; $\mathrm{C}=$ Crohn's disease; $\mathrm{P}=$ polypectomy; $\mathrm{UC}=$ ulcerative colitis.

${ }^{a}$ Age, height and weight are presented as mean $\pm \mathrm{SD}$, other data are shown as number of patients. was a $\chi^{2}$ test. If significant among the groups, the study was stopped. If not significant, a prospective power would be calculated.

All values are expressed as means \pm sD. All datasets were tested for Gaussian distribution by a Kolmogorov-Smirnov test. Between-group analysis was done using a one-way analysis of variance. If significant, post hoc testing was done (Bonferroni correction). Possible changes in within-group observation were tested using a repeated measures analysis of variance test. Between-group observations were analyzed using an independent sample $t$-test with Bonferroni correction for multiple comparisons. Continuous data were time-synchronized and compared every $10 \mathrm{~s}$. Categorical data were analyzed using a Fisher's exact test. Kaplan-Meier survival statistics were applied on the time required to reach a maximum SPRS score.

\section{RESULTS}

Patients' demographics and clinical data were similar among groups (Tables 1 and 2). Three patients were excluded from further analysis due to protocol violation (one from the MCI R group, two from the TCI R group).

Similar times to LOC (Table 2), $\mathrm{C}_{\mathrm{e}}$ prop at LOC $(4.79 \pm 1.31 \mu \mathrm{g} / \mathrm{mL}, 4.41 \pm 0.63 \mu \mathrm{g} / \mathrm{mL}$, and $4.59 \pm$ $0.80 \mu \mathrm{g} / \mathrm{mL}$ for MCI $\mathrm{R}$ group, TCI $\mathrm{R}$ group and placebo group respectively), and BIS at LOC (Table 2) were observed in all groups.

Figure 1 shows the individual BIS and predicted $\mathrm{C}_{\mathrm{p}}$ prop and $\mathrm{C}_{\mathrm{e}}$ prop in the three groups. Similar overall BIS levels were found among groups. $C_{p}$ prop and $\mathrm{C}_{\mathrm{e}}$ prop were significantly different between the TCI R and the placebo group from around $10 \mathrm{~min}$ after starting the study and lasting until the end of the procedure. There were no significant differences in $\mathrm{C}_{\mathrm{e}}$ prop and $\mathrm{C}_{\mathrm{p}}$ prop between the MCI R group and the two other groups.

Figure 2 shows the individual calculated plasma $\left(\mathrm{C}_{\mathrm{p}}\right.$ remi) and effect-site concentrations of remifentanil $\left(\mathrm{C}_{\mathrm{e}}\right.$ remi). Although the bolus dose of remifentanil was given over $2 \mathrm{~min}$ in the MCI group, a clear overshoot in $\mathrm{C}_{\mathrm{p}}$ remi was noted. Large interpatient variability can be observed in the MCI R group for both $\mathrm{C}_{\mathrm{e}}$ remi and $\mathrm{C}_{\mathrm{p}}$ remi.

Table 2. Clinical Data

\begin{tabular}{lcrr}
\hline & MCI R group & TCI R group & Placebo group \\
\hline LOC (s) & $568 \pm 147$ & $529 \pm 96$ & $570 \pm 108$ \\
Start colonoscopy (s) & $674 \pm 219$ & $548 \pm 124$ & $667 \pm 301$ \\
Duration of colonoscopy (s) & $859 \pm 298$ & $997 \pm 465$ & $811 \pm 446$ \\
Duration of deep sedation (s) & $1323 \pm 250$ & $1413 \pm 495$ & $1309 \pm 495$ \\
Total dose of propofol (mg) & $318 \pm 94$ & $289 \pm 81^{*}$ & $381 \pm 162$ \\
Total dose of remifentanil $(\mu \mathrm{g})$ & $40 \pm 8$ & $36 \pm 9$ & $69 \pm 15$ \\
BIS at LOC & $65 \pm 16$ & $61 \pm 15$ \\
\hline
\end{tabular}

Data are presented as mean \pm SD.

$\mathrm{MCl}=$ manually controlled infusion; $\mathrm{LOC}=$ loss of consciousness; $\mathrm{TCl}=$ target-controlled infusion; BIS $=$ bispectral index.

$* P=0.056 \mathrm{TCl} \mathrm{R}$ group versus placebo group. 

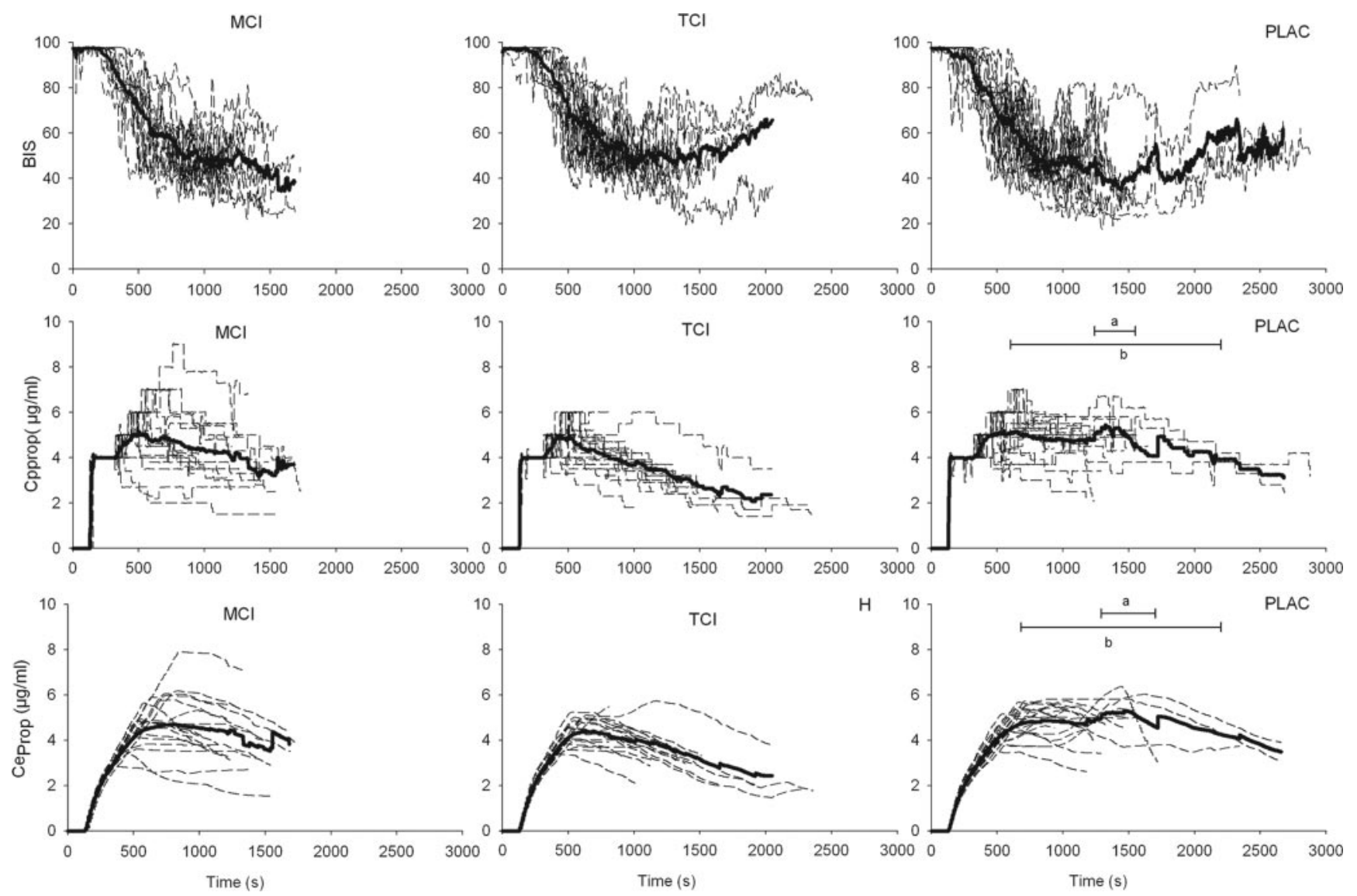

Figure 1. Individual bispectral index (BIS) and predicted plasma and effect-site concentrations of propofol. MCI $=$ manual infusion group; TCI $=$ target-controlled infusion group; PLAC $=$ placebo group. ${ }^{\mathrm{a}}=P<0.05$ between MCI and PLAC and $\mathrm{b}=P<0.05$ between TCI and PLAC.

Figure 2. Individual predicted plasma
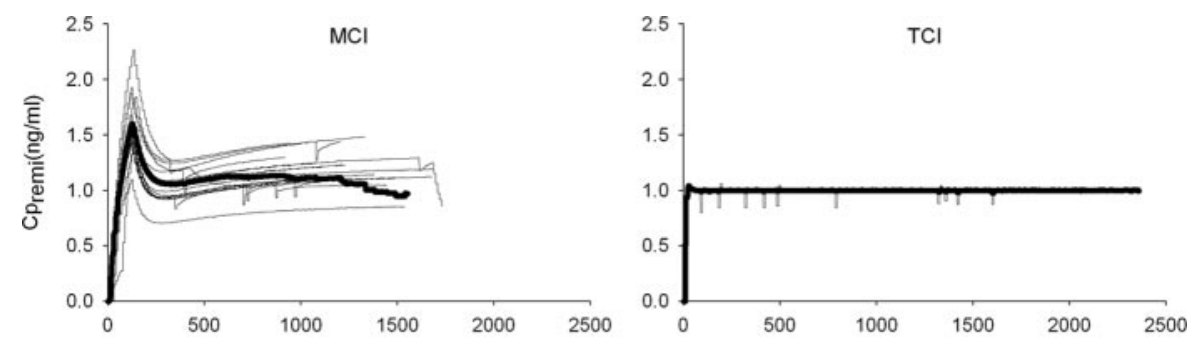
and effect-site concentrations of remifentanil. $\mathrm{MCI}=$ manual infusion group; TCI = target-controlled infusion group.
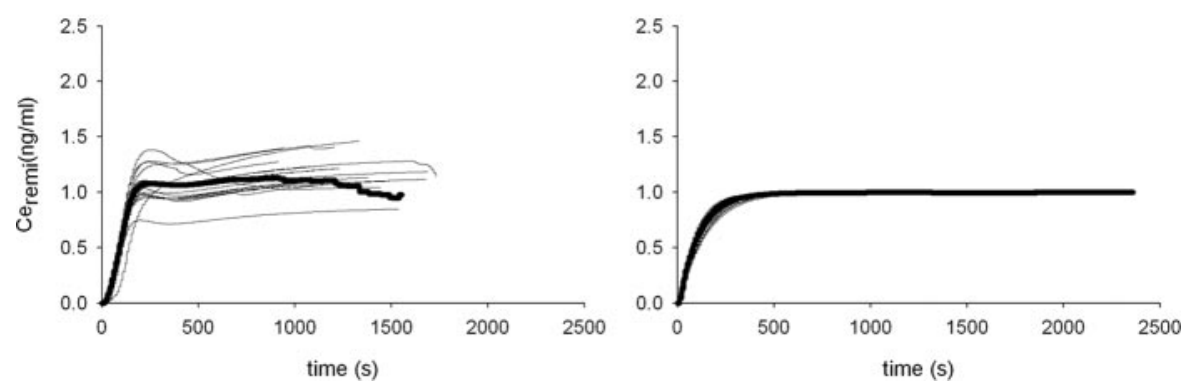

There was no difference in systolic and diastolic blood pressure and in $\mathrm{SaO}_{2}$ among groups. HR was significantly more rapid in the placebo group compared to the TCI R group starting at approximately 10 min after the study drug was initiated and lasting throughout the procedure.

Untoward events are shown in Table 3. Significantly more patients in the placebo group showed movement, cough and hiccup, which transiently interfered with the examination. More respiratory side effects were found in both remifentanil groups. Apnea was significantly more frequent in the $\mathrm{MCI} R$ group compared to the TCI R group. Respiratory side effects were managed by chin lift/jaw thrust in all cases of obstructive respiration, and with gentle assisted mask and bag ventilation to prevent desaturation until 
Table 3. Events

\begin{tabular}{lcccc}
\hline & $\begin{array}{c}\text { MCI R } \\
\text { group } \\
(n=18)\end{array}$ & $\begin{array}{c}\text { TCI R } \\
\text { group } \\
(n=18)\end{array}$ & $\begin{array}{c}\text { Placebo } \\
(n=21)\end{array}$ & $P^{*}$ \\
\hline $\begin{array}{l}\text { Purposeful movement } \\
\text { Nonpurposeful }\end{array}$ & 2 & 5 & 10 & 0.044 \\
$\quad$ movement & 1 & 4 & 4 & 0.342 \\
$\begin{array}{l}\text { Excitatory movement } \\
\text { Obstructive }\end{array}$ & 0 & 0 & 3 & 0.066 \\
$\quad$ respiration & 9 & 10 & 2 & 0.008 \\
$\begin{array}{l}\text { Bradypnea (RR }<6 \\
\text { breaths/min) }\end{array}$ & 8 & 5 & 0 & 0.009 \\
$\begin{array}{l}\text { Apnea } \\
\text { Cough }\end{array}$ & 8 & 2 & 0 & 0.003 \\
Hiccup & 0 & 0 & 4 & 0.025 \\
Drowsiness & 0 & 0 & 3 & 0.066 \\
Nausea/vomiting & 5 & 2 & 3 & 0.373 \\
\hline
\end{tabular}

Data are shown as number of patients.

$\mathrm{MCl}=$ manually controlled infusion; $\mathrm{TCl}=$ target-controlled infusion; $\mathrm{RR}=$ respiratory rate.

* $P$-value between the three groups obtained with a $\chi^{2}$ test as "group * event."

spontaneous ventilation returned in all cases of apnea. Time of onset of apnea was $414 \mathrm{~s}$ and $889 \mathrm{~s}$ for the 2 patients in the TCI R group, and ranged from $373 \mathrm{~s}$ to $1333 \mathrm{~s}$ in the 8 patients of the MCI R group.

$\mathrm{C}_{\mathrm{e}}$ prop at recovery of consciousness and recovery times were comparable among the three groups (Table 4). Survival statistics showed that the time to reach a maximum SPRS did not differ among groups.

Post hoc analysis of the pharmacokinetic data revealed significant differences among the groups. Time to reach $\mathrm{C}_{\mathrm{e}}$ remi of $0.95 \mathrm{ng} / \mathrm{mL}(95 \%$ of the target concentration) was $162.65 \pm 33.93 \mathrm{~s}$ in the MCI R group versus $325.78 \pm 56.41 \mathrm{~s}$ in the TCI $\mathrm{R}$ group $(P<0.05)$. Maximum $\mathrm{C}_{\mathrm{p}}$ remi $\left(\mathrm{C}_{\mathrm{p}}\right.$ remi $\left.\mathrm{imax}_{\text {max }}\right)$ and $\mathrm{C}_{\mathrm{e}}$ remi $\left(\mathrm{C}_{\mathrm{e}}\right.$ remi $\left._{\text {max }}\right)$ were significantly higher in the MCI R compared to the TCI R group. Maximum $\mathrm{C}_{\mathrm{e}}$ prop $\left(\mathrm{C}_{\mathrm{e}}\right.$ prop $\left.\mathrm{p}_{\max }\right)$ was significantly lower in the TCI R group compared to the placebo group (Table 5).

When subdividing the MCI R group into patients who experienced apnea $(n=8)$ versus patients who did not $(n=10)$, we found a significantly higher $\mathrm{C}_{\mathrm{p}}$ remi $\mathrm{max}_{\text {max }}$ in the apnea group $(1.797 \pm 0.324 \mathrm{ng} / \mathrm{mL}$ vs $1.490 \pm 0.193 \mathrm{ng} / \mathrm{mL}$ in the no apnea group). $\mathrm{C}_{\mathrm{e}}$ remi $_{\text {max }}$ had a tendency to be higher in the apnea group $(P=0.07)$. $\mathrm{C}_{\mathrm{e}}$ prop $_{\max }$ was not significantly

Table 4. Recovery Data

\begin{tabular}{lccc}
\hline & $\begin{array}{c}\text { MCI R } \\
\text { group }\end{array}$ & $\begin{array}{c}\text { TCI R } \\
\text { group }\end{array}$ & $\begin{array}{c}\text { Placebo } \\
\text { group }\end{array}$ \\
\hline $\begin{array}{c}\text { C } \text { prop at ROC } \\
(\mu \mathrm{g} / \mathrm{mL})\end{array}$ & $1.80 \pm 0.88$ & $1.69 \pm 0.48$ & $2.13 \pm 0.56$ \\
$\begin{array}{c}\text { Time to open eyes (s) } \\
\text { Time to follow } \\
\quad \text { command (s) }\end{array}$ & $350 \pm 168$ & $240 \pm 116$ & $302 \pm 138$ \\
$\begin{array}{c}\text { Time to state date of } \\
\text { birth (s) }\end{array}$ & $348 \pm 151$ & $262 \pm 125$ & $304 \pm 120$ \\
\hline
\end{tabular}

Data are presented as mean $\pm \mathrm{SD}$.

$\mathrm{MCl}=$ manually controlled infusion; $\mathrm{TCl}=$ target-controlled infusion; $\mathrm{ROC}=$ recovery of consciousness; $\mathrm{C}_{\mathrm{e}}$ prop $=$ effect-site concentration of propofol.
Table 5. Maximum Predicted Plasma and Effect-Site Concentrations

\begin{tabular}{|c|c|c|c|}
\hline & $\begin{array}{l}\text { MCI R } \\
\text { group }\end{array}$ & $\begin{array}{l}\text { TCI R } \\
\text { group }\end{array}$ & $\begin{array}{l}\text { Placebo } \\
\text { group }\end{array}$ \\
\hline $\begin{array}{r}\mathrm{C}_{\mathrm{p}} \mathrm{remi}_{\max } \\
(\mathrm{ng} / \mathrm{mL})\end{array}$ & $1.627 \pm 0.296$ & $1.047 \pm 0.110^{*}$ & - \\
\hline $\begin{array}{r}\mathrm{C}_{\mathrm{e}} \mathrm{remi}_{\max } \\
(\mathrm{ng} / \mathrm{mL})\end{array}$ & $1.223 \pm 0.160$ & $0.999 \pm 0.001^{*}$ & - \\
\hline $\begin{array}{r}\mathrm{C}_{\mathrm{e}} \text { prop }_{\max } \\
(\mu \mathrm{g} / \mathrm{mL})\end{array}$ & $4.957 \pm 1.208$ & $4.520 \pm 0.666+$ & $5.218 \pm 0.706$ \\
\hline \multicolumn{4}{|c|}{ Data are presented as mean \pm SD. } \\
\hline \multicolumn{4}{|c|}{ 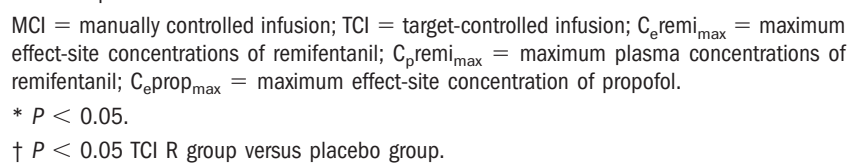 } \\
\hline
\end{tabular}

different $(4.70 \pm 1.24 \mu \mathrm{g} / \mathrm{mL}$ vs $5.16 \pm 1.20 \mu \mathrm{g} / \mathrm{mL}$ in respectively the apnea and the no apnea group).

\section{DISCUSSION}

This study was conducted to investigate two questions: first, if the advantages of the addition of remifentanil to propofol in spontaneously breathing patients surpasses the disadvantages of the combination of these two products, and second, if administration of remifentanil via TCI optimizes drug delivery, resulting in a safer and more reliable technique for coadministration of propofol and remifentanil.

We found that the addition of remifentanil to propofol resulted in less movement, hiccup and cough and thus the combination of remifentanil and propofol offered better conditions for colonoscopy than propofol used as a single drug. We also found that administering remifentanil via TCI offered further benefit compared to manual administration of remifentanil, as remifentanil TCI reduced propofol requirements and decreased the incidence of respiratory depression.

Previous studies showed that a single drug is unable to manage amnesia, analgesia, and immobility during procedural deep sedation. ${ }^{15}$ This was confirmed in our study, in which movement, cough and hiccup in the group receiving only propofol frequently interfered with the examination, making the conditions for colonoscopy less beneficial. This proves the difficulty of managing noxious stimuli when only using propofol. We hypothesized that the combined use of propofol-remifentanil might result in optimal control of all components of the anesthetic state during procedural deep sedation. When coadministering remifentanil to propofol, we found a decreased incidence of somatic responses. Unfortunately, remifentanil is a potent ventilatory depressant. Nieuwenhuijs et al..$^{5}$ studied the remifentanil-propofol interaction on cardiorespiratory control using the technique of response surface modeling. They observed strikingly synergistic respiratory depression when remifentanil and propofol are combined, even in low concentrations. When observing the ventilation- $\mathrm{CO}_{2}$ response curve, the combined administration of remifentanil 
and propofol yielded both a rightward shift of the response curve (typical $\mu$-opioid effect) and a reduction in the slope of the curve (typical effect of a hypnotic/sedative). We hypothesized that administration of remifentanil via TCI would optimize drug delivery, resulting in a lower incidence of respiratory side effects.

TCI has been developed to optimize drug delivery by targeting a specific therapeutic drug concentration in a specific body compartment. The drug's typical pharmacokinetic behavior was first characterized from clinical pharmacology studies in widely different patient populations and implemented physiologic or disease state covariates. All these data are preprogrammed into the multi-compartmental pharmacokinetic model of the TCI system, minutely describing the distribution and elimination of the drug within the body. The TCI system calculates the infusion rate to achieve and maintain the defined target concentration as fast and accurately as possible without overshoot. Because the drug accumulates in the body, the system frequently recalculates the appropriate drug dosage and updates the infusion rate, enabling a steady-state concentration of drug. In other words, TCI systems reduce both time-dependent variability (by continuously updating the infusion rate) and interpatient variability (by implementing the effect of covariates on pharmacokinetics). TCI systems use complex mathematical models to compute the drug dosage. It is impossible to perform these complex calculations and control drug administration with the same accuracy when using MCI systems. ${ }^{6}$

There are no studies demonstrating a clear patient benefit when using remifentanil through TCI instead of manually controlled remifentanil administration. Obviously, to evaluate this, we needed comparable remifentanil concentrations in the two study groups. Therefore, we first performed pharmacokinetic simulations, using the RUGLOOP II program, to ensure similar calculated remifentanil effect-site concentrations, as well as a similar concentration trajectory in the two remifentanil groups. A bolus dose of 0.25 $\mu \mathrm{g} / \mathrm{kg}$ given over $2 \mathrm{~min}$, followed by a continuous infusion of $0.05 \mu \mathrm{g} \cdot \mathrm{kg}^{-1} \cdot \mathrm{min}^{-1}$ gave the best approximation of the target $\mathrm{C}_{\mathrm{e}}$ remi of $1 \mathrm{ng} / \mathrm{mL}$. As shown in Figure 2, the simulation was very accurate since the mean $\mathrm{C}_{\mathrm{e}}$ remi approached $1 \mathrm{ng} / \mathrm{mL}$ in the MCI R group.

Despite our efforts to imitate the TCI profile as closely as possible, overshoot, interpatient variability, and accumulation of remifentanil was noted in the MCI group. This is clearly depicted in Figure 2. Post hoc analysis of our pharmacokinetic data also revealed that $\mathrm{C}_{\mathrm{p}}$ remi $_{\max }$ and $\mathrm{C}_{\mathrm{e}}$ remi $\mathrm{max}_{\max }$ were significantly higher in the MCI R group compared to the TCI R group.

We realize that concentrations reported by the TCI system are predicted, not true concentrations, and therefore the difference between the MCI R and the TCI R group is a function of the pharmacokinetic-dynamic model used. We did not measure remifentanil plasma concentrations, since the pharmacokinetic-dynamic model we used has been demonstrated as adequately accurate in predicting plasma and effect-site concentrations of remifentanil. ${ }^{10,11}$ However, higher variability, overshoot and accumulation of drug in the MCI group compared to the TCI group is well known and was not surprising, since, as mentioned before, TCI evaluates the complexity of the drug pharmacokinetic characteristics, which manual administration regimen cannot. ${ }^{6}$

In our study, it is remarkable that, although we designed our MCI group to receive virtually the same effect-site concentration as our TCI group, we found significant differences. We found a significantly higher incidence of apnea of the MCI R group compared to the TCI R group (Table 3). We also found that remifentanil administered via TCI resulted in a decrease in propofol requirements (Table 5, Fig. 1).

It is possible that the difference in incidence of apnea is solely attributable to a dosing difference. When comparing patients who experienced apnea versus patients who did not, $\mathrm{C}_{\mathrm{p}}$ remi $_{\max }$ was significantly higher in the apnea group. If the difference in incidence of apnea was indeed due to the dosing difference, this means that the pharmacokinetic inaccuracy, which is inherent to manual controlled infusions, has important pharmacodynamic repercussions. This is especially important in situations in which there is little room for error, as is the case with remifentanil in spontaneously breathing patients.

Another explanation for the difference in apnea between the MCI R and the TCI R group could be the more bolus type of administration of remifentanil at the beginning of the administration in the MCI R group. In the MCI R group, $\mathrm{C}_{\mathrm{e}}$ remi of $0.95 \mathrm{ng} / \mathrm{mL}$ was reached twice as fast as in the TCI R group. One would suppose that, if the difference was due to this more rapid bolus administration in the MCI $\mathrm{R}$ group, the major difference between the groups would have been at induction. However we found no difference in time of onset of apnea between the two groups. One reason could be, as stated by Bouillon et al., ${ }^{16}$ that RR is not a good indicator for respiratory depression. They state that an increase in tidal volume variability is a better predictor of respiratory depression than decreased RR. Since this was a study performed in a clinical situation the tools to measure tidal volume variability were not available.

Besides the difference in incidence in apnea, we also found a difference in propofol concentrations among the study groups. $\mathrm{C}_{\mathrm{p}}$ prop, $\mathrm{C}_{\mathrm{e}}$ prop, and $\mathrm{C}_{\mathrm{e}}$ prop ${ }_{\max }$ were significantly lower in the TCI R group compared to the placebo group, whereas the propofol concentrations in the MCI group did not differ from the two other groups. According to the study protocol, the target $\mathrm{C}_{\mathrm{p}}$ prop was decreased by $0.5 \mu \mathrm{g} / \mathrm{mL}$ if the patient was unresponsive for $3 \mathrm{~min}$. In Figure 1, we depicted the $\mathrm{C}_{\mathrm{p}}$ prop of all patients individually. From this figure, 
it is clear that in the TCI group the decrease of the propofol target concentration is consistent, whereas in the MCI group decreasing the propofol target concentration was more burdensome. We presume that this was due to the large interindividual variability in remifentanil concentrations in the MCI group making deep sedation far less manageable.

In conclusion, we have shown that the addition of remifentanil to propofol provides more stable anesthetic conditions compared with propofol used as a single drug. Administering remifentanil via TCI during spontaneous ventilation results in a decrease in propofol dosing and in a lower incidence in apnea compared to remifentanil administered via $\mathrm{MCI}$.

Since the combination of propofol and remifentanil, even in TCI, still results in strikingly synergistic respiratory depression, careful monitoring of respiratory function and appropriate skills in the recognition and treatment of inadequate respiration remain mandatory.

\section{REFERENCES}

1. Moerman A, Struys MMRF, Vereecke H, Herregods L, De Vos M, Mortier E. Remifentanil used to supplement propofol does not improve quality of sedation during spontaneous respiration. J Clin Anesth 2004;16:237-43

2. Murdoch JA, Hyde RA, Kenny GN. Target-controlled remifentanil in combination with propofol for spontaneously breathing day-case patients. Anaesthesia 1999;54:1028-31

3. Peacock JE, Luntley JB, $\mathrm{O}^{\prime}$ Connor B, et al. Remifentanil in combination with propofol for spontaneous ventilation anaesthesia. Br J Anaesth 1998;80:509-11

4. Joo HS, Perks WJ, Kataoka MT, Errett L, Pace K, Honey RJ. A comparison of patient-controlled sedation using either remifentanil or remifentanil-propofol for shock wave lithotripsy. Anesth Analg 2001;93:1227-32
5. Nieuwenhuijs D, Olofsen E, Romberg R, Sarton E, Ward D, Englbers F, Vuyk J, Mooren R, Teppema L, Dahan A. Response surface modeling of remifentanil-propofol interaction on cardiorespiratory control and bispectral index. Anesthesiology 2003;98:312-22

6. Egan TD. Target-controlled drug delivery. Anesthesiology 2003;99:1214-19

7. Babenco HD, Conard PF, Gross JB. The pharmacodynamic effect of a remifentanil bolus on ventilatory control. Anesthesiology 2000;92:393-8

8. Schnider TW, Minto CF, Shafer SL, Gambus PL, Andresen C, Goodale DB, Youngs EJ. The influence of age on propofol pharmacodynamics. Anesthesiology 1999;90:1502-16

9. Schnider TW, Minto CF, Gambus PL, Andresen C, Goodale DB, Shafer SL, Youngs EJ. The influence of method of administration and covariates on the pharmacokinetics of propofol in adult volunteers. Anesthesiology 1998;88:1170-82

10. Minto CF, Schnider TW, Egan TD, Youngs E, Lemmens HJ, Gambus PL, Billard V, Hoke JF, Moore KH, Hermann DJ, Muir KT, Mandema JW, Shafer SL. Influence of age and gender on the pharmacokinetics and pharmacodynamics of remifentanil: I. Model development. Anesthesiology 1997;86:10-23

11. Minto CF, Schnider TW, Shafer SL. Pharmacokinetics and pharmacodynamics of remifentanil: II. Model application. Anesthesiology 1997;86:24-33

12. Shafer SL, Gregg KM. Algorithms to rapidly achieve and maintain stable drug concentrations at the site of drug effect with a computer-controlled infusion pump. J Pharmacokinet Biopharm 1992;20:147-69

13. Struys MM, De Smet T, Depoorter B, Versichelen LF, Dumortier FJ, Shafer SL, Rolly G. Comparison of plasma compartment versus two methods for effect compartment-controlled target-controlled infusion for propofol. Anesthesiology 2000;92:399-406

14. Steward DJ. A simplified scoring system for the postoperative recovery room. Can Anaesth Soc J 1975;22:111-13

15. Moerman A, Foubert L, Herregods L, Struys MM, De Wolf D, De Looze D, De Vos M, Mortier E. Propofol versus remifentanil for monitored anaesthesia care during colonoscopy. Eur J Anaesthesiol 2003;20:461-6

16. Bouillon T, Bruhn J, Roepcke H, Hoeft A. Opioid-induced respiratory depression is associated with increased tidal volume variability. Eur J Anaesthesiol 2003;20:127-33 